\title{
Vers l'implentation de la cartographie du continuum archéologique. Nouvelles perspectives et limites actuelles de l'archéologie préventive en Italie.
}

\author{
Towards mapping the archaeological continuum. New perspectives and \\ current limitations in Planning Led Archaeology in Italy.
}

\section{Stefano Campana ${ }^{1}$}

\author{
${ }^{1}$ University of Siena, Ancient Topography, Landscape Archaeology \& Remote Sensing LAB Department of History and \\ Cultural Heritage, Italy, campana@unisi.it
}

\begin{abstract}
The paper discusses both theory and practice in the application of the Italian domestic law, which has applied since 2006 to any kind of public new construction or to the modification of existing structures. The author argues, based on two of his own projects, BREBEMI and EMPTYSCAPES, that there are both shortcomings and new opportunities within Planning Led Archaeology. Projects from the last decade, in Italy and elsewhere, have demonstrated the potential effectiveness of new approaches to pre-development evaluation in the operation of the current legal and scientific framework that may make it possible to overcome some severe limitations in current practice.
\end{abstract}

KEYWORDS. Planning Led Archaeology, Rescue Archaeology, Absence of evidence, Archaeological, Continuum.

'not much has changed in field archaeology over the last 20 years...The reason is easily explained. As the commercial profession was formed, field method become standardised and, due largely to national economic and political pressures, it got struck in its ways. Standardised practice was where the money was'(Carver et al. 2015: vii)

'But the method must be judged by its potential, rather than by its early and experimental attainments' (Bintliff \& Snodgrass 1988: 69)

\section{Introduction}

The Italian term 'Archeologia Preventiva' can be translated into English as Planning Led Archaeology (PLA). The Italian law on this subject was first promulgated in 2006. It may be useful to begin discussion here with a consideration of the purpose behind the law and a statement of what PLA is not. Starting from the concept that archaeological remains are a finite and irreplaceable resource, their presence should be a material consideration in all applications for new development, as is the established practice in many other European countries. It is widely accepted that many development proposals will affect archaeological deposits and that harmful effects must be therefore mitigated whenever possible. Moreover, the new law aims to develop planning processes that will minimize unforeseen problems during development and reduce or eliminate calls for emergency work. Here, it is crucial to understand that PLA is not 'rescue' or 'salvage' archaeology: its aim is to contain and minimize the need for these responses. Indeed, the whole purpose of the law revolves around the importance of evaluating an area or a landscape for its archaeological potential in advance of development, in order to inform subsequent planning and management decisions.

So-called Rescue Archaeology has been widely understood to consist of archaeological survey, recording and excavation carried out in areas threatened by urban or other developments. The public development may include, but is not limited to, motorway, railway, and major construction 
projects for major buildings, sport facilities, shopping malls and so forth. Unlike survey and excavation work within the academic sphere, Rescue Archaeology is often carried out under severe pressure of time. It is undertaken primarily on sites that are about to be destroyed or, occasionally, as a protective measure to preserve archaeological features identified when construction work is already in progress beneath urban or rural areas.

The term Rescue Archaeology, and its practice, are largely restricted to Europe, North America, South America and East Asia. In Italy the term is virtually synonymous with rescue excavation, in the form of a vast number of small-scale 'test' excavations or trial trenching of one kind or another. Currently, the relationship between Rescue Archaeology and Planning Led Archaeology constitutes something of an archaeological 'hot potato', a problem difficult to deal with in Italy as well in many other countries. In the author's view it would be a mistake to consider this issue just as a technical and procedural one. It represents much more than that: indeed, it poses a real cultural challenge which might lead, as suggested in this paper, to new lines of thought in the field of archaeology, conservation and heritage management, as well as in the detection of what might be called the 'archaeological continuum' in both rural and formerly urban landscapes. Moreover, bearing in mind the systematic and on-going reduction of funding for archaeological research within the institutional framework, it is easy to predict - on the principle that 'the polluter pays', now currently followed in Italy as in many other European countries - that most of the funding destined for use within Italian archaeology will in future be devoted almost exclusively to Planning Led Archaeology. This will most likely lead to financial speculation on the part of powerful lobbies and large investors.

However, if Rescue Archaeology arose from the interest of reducing the destruction of archaeology uncovered during urban development or re-development already in progress, Planning Led Archaeology's starting point is completely different: it rests securely within the planning process in advance of actual development. In this new perspective archaeology should be considered a key consideration in urban and landscape planning, alongside geology, hydrology and other environmental factors. It should be clear that Planning Led Archaeology and Rescue Archaeology are completely different approaches - they are entirely opposite reactions both in theory and in practice. Essentially, the aim of Planning Led Archaeology is to replace Rescue Archaeology as much as ever possible, making interventions through 'rescue' or 'salvage' work exceptional, necessary only when diagnostic and predictive archaeology have failed.

It should be obvious from these comments that, to apply any effective planning approach, specific and well-defined legislation is necessary. Timing is of the essence here: to be really effective, substantive archaeological information should be available from the very start of feasibility studies when major construction projects are first contemplated. Archaeological evaluation, and the response to its conclusions, should be undertaken before any planning permission is granted. If this condition is not satisfied the balance of necessity reverts in one way or another away from Planning Led Archaeology to the manifest inadequacies of Rescue Archaeology.

\section{Current 'rules of the game'}

Since the introduction of the new law in 2006 it has been a compulsory requirement that an archaeological impact assessment, with related report, should be completed at the beginning of any public development project which raises public concern, such as new urban, industrial or infrastructure development projects or the modification of existing structure' ${ }^{1}$. The Public

\footnotetext{
${ }^{1}$ At the time of writing in the winter of 2016 the Superintendence and the Public Procurement Code were undergoing radical reforms, which may affect future procedures within Planning Led Archaeology. 
Procurement Code (as improved from time to time) quotes two main steps, each involving different decision-making processes and outcomes (Gull 2015).

Phase 1 happened at preliminary project stage in advance of any planning decision being made $^{2}$. A developer tenders for the work to be done and chooses an archaeological organization (commercial company and University) or an archaeological consultant to retain. The scientific direction of the work is under the responsibility of local superintendence.

Phase 1 takes place at the preliminary stage, in advance of any planning decision being made ${ }^{3}$. A developer (or a public body) proposes that construction work should be undertaken and retains an archaeological organization - a commercial company, a University or a private archaeological consultant - to compile an impact assessment report. The overall supervision of the process lies under the responsibility of the local Superintendence. In this phase the evaluation report is based on the collection of background data from existing archaeological publications, historical cartography, place- name registers, field-walking survey and geo-archaeological studies etc. Mention is also made in the law of the opportunity to take account of evidence from vertical air photgraphs (though, unfortunately, without any reference to oblique photography from exploratory reconnaissance). Information may also be submitted, when possible or useful, from the collection and analysis of LiDAR data. In some cases further analysis might be required for individual target areas through geophysical prospection or small-scale test excavation. Following the submission of a satisfactory evaluation report the Superintendence has three choices. The first is to advise the developer that work on site can start without further investigation, but though compulsory implementation of systematic archaeological watching brief ${ }^{4}$. The second consists in the improvement of the first phase of evaluation by undertaking further investigations based on borehole survey, geophysical or geochemical prospection, or trial trenching. The third option, based on the results of an original or improved evaluation report attesting the presence of anthropic/archaeological features (structures, cultural material or any other evidence) involves an appraisal of the balance between the need or nature of the intended development and the importance of the threatened archaeological heritage. Theoretically, the development could be stopped at this stage if there is a clear mismatch between the need for development and the interests of archaeological conservation.

Phase 2, assuming that major archaeological investigation is necessary, takes place within the general project framework at the stage of detailed design and work-planning ${ }^{5}$. The first step in this case is the framing of preliminary and then detailed proposals for the conduct of a systematic archaeological investigation, usually involving large-scale archaeological excavation. Even at this stage the developer could have a change of mind and either suspend the project or look into lowercost options for responding to the needs of heritage conservation. This kind of decision, of course, can be very painful, putting developers as well as institutions in an extremely uncomfortable situation. This simply emphasises the importance of the work involved in Phase 1 of the process.

\section{Current approaches in practice}

The new law gives archaeologists, archaeological consultants and institutions the chance to start afresh with a new approach to methodologies developed in the field of landscape archaeology over the past forty years or so, for instance, the opportunity, as clearly permitted within the wording

\footnotetext{
${ }^{2}$ D.Lgs. $163 / 2006$, art.95.

${ }^{3}$ D.Lgs. 163/2006, art.95

${ }^{4}$ A Watching Brief involves the presence of one or more archaeologists on site to monitor ground-works in progress, to record any finds or features revealed, and in the event of major discoveries to negotiate for a pause in the construction work while emergency excavations can be carried out (Greene \& Moore 2010).

${ }^{5}$ D.Lgs. 163/2006, art.96.

(c) 2017 ISTE OpenScience - Published by ISTE Ltd. London, UK - openscience.fr 
of the law, to undertake non-destructive investigations within Phase 1 of the evaluation process. This might entail, as happens in the field of medical diagnostics or also on crime scenes, investigations to acquire detailed evidence that might otherwise remain undiscovered or invisible. The result would hopefully help to ensure a more effective and well-focused information base so as to inform and improve the planning process. At the same time, especially for major infrastructure projects in rural contexts, such as motorway developments, this prior investigation could involve the adoption of new approaches in place of the kind of topographical research that results in the depiction of 'sites' represented by dots on distribution maps, surrounded by a sea of 'emptiness' (Powlesland 2009). Indeed, within that kind of approach, however carefully undertaken, a massive amount of potentially recoverable information necessarily remains undetected between the so-called 'sites'. To give us an understanding of past landscapes in such a context, and therefore a reliable evaluation of the archaeological potential as a trustworthy support for the planning process, it should surely become mandatory (as an ethical and practical imperative) to map the archaeological landscape as an all-embracing 'continuum' across time, using whatever technical means and methodologies are now available. Gaps, uncertainties and absences of evidence must be confronted and reduced as much as ever possible.

Sadly, current interpretation and implementation of the law takes little or no account of this need or opportunity, still placing reliance on what can best be described as 'rescue excavation' in the form of large-scale mechanical stripping followed by little more than small-scale test excavations within 'traditional' or even entirely outmoded archaeological methods.

In the author's experience, this prevailing approach gives little weight to Phase 1 of the process. As currently applied, this stage is treated in practice as little more than a 'desktop' exercise, primarily based on the collection of published information (archaeology, place-names and landscape physiography etc) and occasionally by a preliminary site visual inspection. This is an approach, which has been shown by academic studies from the 1990s onwards to be totally unrepresentative of reality, and therefore equally inadequate as support for a satisfactory analysis of the archaeological potential of the landscape within the development area. Within this antiquated approach air-photo interpretation is sometimes taken into account but active field survey is undertaken only rarely and LiDAR data is almost never brought into consideration.

This kind of preparatory work, based for the most part on existing knowledge rather than the outcome of systematic field-walking survey (not considering the contribution of other kind of surveys), has long ago been shown to reveal, in the Italian context, no more than $5-10 \%$ of the potentially available information about the existence or character of archaeological features, especially within the open countryside (Guaitoli 1997; Francovich et al. 2000).

As a logical consequence, a 'negative' or inconclusive assessment made under this interpretation of Phase 1 would lead the superintendence in most cases to advise the developer that construction work can start without further investigation. In practice, however, this rarely happens since the staffs in the superintendence are fully aware of the uncertainties involved in this kind of Phase 1 report. They therefore, prudently, suggest further investigation, generally based on trial trenching. Or alternatively, and more likely, they move directly to Phase 2. This has its drawbacks, of course. Indeed, as aforementioned, phase 2 , is based almost only on large-scale archaeological excavation and placed at the latest planning phase (design stage or working plan). So, in practice, instead of gaining any real advantage from application of the new law we are substantially back to 'rescue' archaeology, meaning a high probability of unforeseen discoveries, limited possibilities for modifying the project design, high pressure from politicians and/or the developer's shareholders, and inadequate time to carry out whatever archaeological fieldwork becomes necessary. This feeble implementation of Phase 1, with investigation under Phase 2 grounded primarily in mechanical stripping and emergency excavation in response to a systematic watching brief, is in the author's view dangerous and potentially very damaging to the country's archaeological and landscape 
heritage. Within this kind of procedure it is often difficult, both intellectually and physically, to identify archaeological features, with the result that a large amount of 'perishable' evidence or ephemeral cultural information may inevitably be lost. Moreover, it must never be forgotten that any archaeological excavation is an inherently destructive and irreversible process; large-scale mechanical stripping by caterpillar merely exacerbates this problem, often dramatically so. There should surely be no argument about these conclusions - they are clearly consistent with longstanding international recommendation on the protection of the archaeological heritage, as set out for instance in the Valletta Convention of 1992, only recently - and very belatedly - incorporated into domestic law by the Italian government or in the Faro Convention on the Value of Cultural Heritage for Society (2005).

\section{Past and on-going experience}

\section{The BREBEMI project}

In 2009 the author was serving a double role as a faculty member of the University of Siena (teaching Ancient Topography) but also, in collaboration with a number of colleagues, acting as executive president of a newly formed spin-off company aimed at transferring to the marketplace some of the expertise developed within the University's Laboratory of Landscape Archaeology and Remote Sensing. Early that year he received a call from a group of contractors who had underestimated the possible archaeological implications of a project to which they were already committed, the construction in northern Italy of a $100 \mathrm{~km}$ motorway linking the cities of BREscia, BErgamo and MIlan (hence the project's acronym BREBEMI). The project had been initiated before the new law came into effect so any kind of assessment under Phase 1 was already out of the question. The superintendence in Lombardy required the motorway contractors to carry out 'excavation by surface stripping' over the whole of the area affected by the motorway construction. In the view of the contractors that request was both logistically and financially nonsensical since it would have increased the cost and time-span of the project to an unmanageable degree. As a result, the contractors were looking for an alternative archaeological solution, which might prove acceptable to the superintendence.

By chance - or misfortune depending from one's point of view - this gave rise to the first opportunity in Italy to test the operation of the new law by undertaking the systematic and innovative use of a range of non-invasive techniques to minimise the risk of archaeological recovery that would inevitably be caused by a large infrastructure project of this kind. The archaeological strategy devised for the resulting assessment (Figure 1, left) envisaged the systematic collection of historical and geographical data, the interpretation of documentary sources, geomorphological studies, the analysis of existing vertical air-photographs and the initiation of oblique aerial photography and LiDAR survey along the whole of the motorway corridor, in some cases including a substantial buffer zone on either side.

A crucial innovation in the strategy, however, was the decision to collect large-scale contiguous geophysical data, both magnetic and geo-electrical, along the course of the motorway corridor, building on an approach successfully applied in a variety of contexts in Italy, France and above all the UK (Campana \& Piro 2009). Systematic test excavations were also planned to explore or verify anomalies identified by any or all of these techniques. Independently, the regional superintendence designed a pattern of random test trenches amounting to a $5 \%$ sample of the motorway corridor (Campana \& Dabas 2011). 

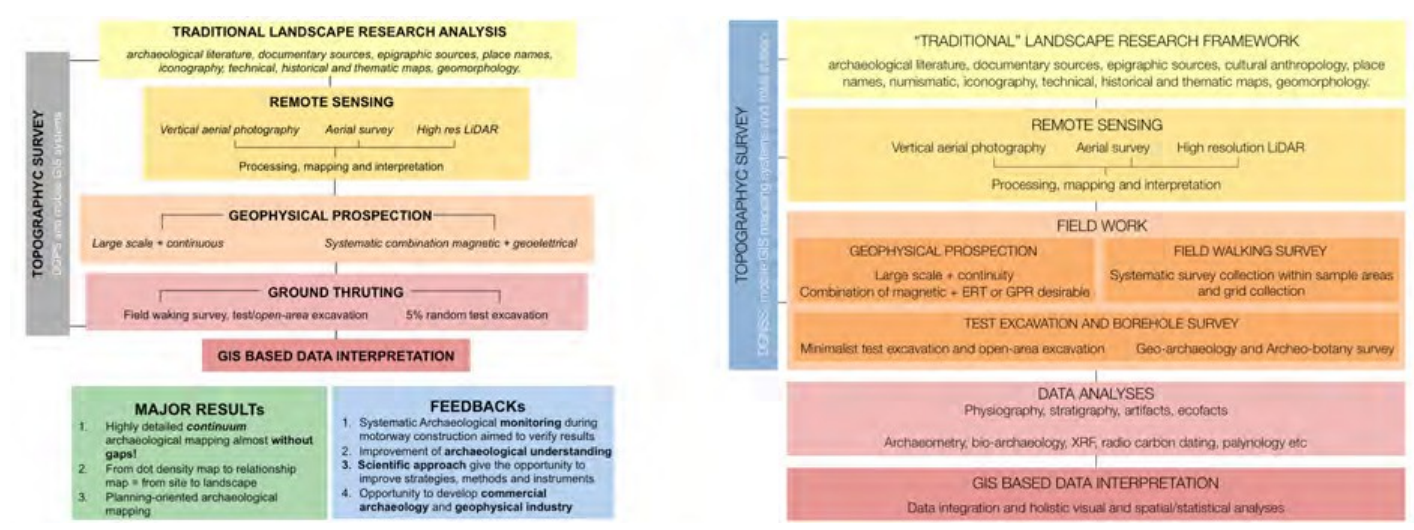

Figure 1. Left: the pipeline of information and activities within the BREBEMI project. Right: the research framework of the Emptyscapes project.

Within the BREBEMI company a GIS was designed to integrate, manage and share (in real time with the contractors as well the Superintendence of Lombard Region) the collected data at all stages from data acquisition to interpretation and field checking, so as to assess any significant findings and to develop 'predictive' archaeological models. The aim was to reduce the degree of uncertainty about the possible presence of archaeological remains by producing a detailed and continuous map based on a holistic and essentially non-destructive approach to landscape archaeology, allowing the superintendence and contractors to plan their activities in the best manner possible. The archaeological assessment started in May 2009 and over no more than four months of multifaceted investigation it proved possible to collect and interpret a vast amount of data, greatly enriching the archaeological and environmental understanding of this particular stretch of landscape. The collection and interpretation of this data also helped the motorway contractors to plan in advance for archaeological work, which might otherwise have necessitated delays and extra expenditure during the construction work. Moreover, an outstandingly rich, continuous and detailed body of archaeological documentation was created for the whole of the area affected by the motorway, providing at the very worst a degree of 'preservation by record'.

This experience also represented an invaluable opportunity for sharpening and deepening ideas about Planning Led Archaeology in the Italian context, especially as regards the advantages and disadvantages of the range of techniques and working methods applied for the first time to such a large extent within the BREBEMI project. Naturally, there are no an easy answers to the complex questions raised by the introduction of Planning Led Archaeology. The BREBEMI project, however, made it possible for a consortium of archaeologists and others to collect a huge amount of potentially informative data in a very short time: 438 ha of geophysical measurements (both magnetic and geo-electrical), informative oblique air-photography, $150 \mathrm{~km}^{2}$ of high-resolution LiDAR data, hundreds of specifically-targeted test excavations, evidence for thousands of archaeological features as well as for topography, geomorphology and other environmental factors (Campana \& Dabas 2011).

The assessment work failed to detect subsequently discovered archaeological features in only one instance, very early in the evaluation process when only a limited range of evidence was available $^{6}$. The mechanical excavation and trial trenching specified by the superintendence also

\footnotetext{
${ }^{6}$ This was the first area that has been investigated: Fara Olivana (Bergamo). Unfortunately our work started with the necessity to cover this area in a very short time. In these circumstance, in contrast with the carefully planned pipeline illustrated in Figure 1, we were forced provide our evaluation based only on the results of geophysical survey, unsupported by any matching information about evidence that might have existed in the archaeological literature, in place-name studies or in historical map etc (these and various other forms of information only became available only at a more advanced stage of work. So we worked almost blind. However, the achievement of the broader picture allow us to make the following considerations:

1. GIS-based superimposing of topographic survey of individual burials and geophysical signals allow us to identify a series of value ranges able to characterize with higher probability this kind of evidence.

2. Mapping archaeological literature, place name, historical map and so showed clearly widespread evidence of small cemetery placed at approximately $700-900 \mathrm{~m}$.

(c) 2017 ISTE OpenScience - Published by ISTE Ltd. London, UK - openscience.fr 
failed, showing some worryingly serious limitations. However, the point here is not to argue about which approach is the better. In the right circumstances, and deployed in the right way, both can be useful and in some instances mutually complementary. The key issue is that while non-destructive methods, and skilled interpretation of the resulting data, can be expected to improve in reliability over time, the same can not be said for the investigation based on 'in the field' reaction to mechanical stripping rather than on prior survey and targeted on-site recording and stratigraphical excavation. Another key point is that it is not possible to validate the results of this 'reactive' kind of excavation work. Every archaeologist knows that excavation destroys the evidence upon which it relies, especially if it is not carried out within a suitable methodological framework and timescale. By contrast it is entirely possible - and desirable - to use stratigraphical excavation to verify and interpret potential archaeological features recorded initially through geophysical or other forms of non-invasive prospection.

\section{The Emptyscapes project}

The second example that seems worth presenting here revolves around a two-year project Emptyscapes - being undertaken in 2014-2016 by the author at Cambridge University with the aid of funding from the Marie Curie scheme of the European Union. The archaeological questions, methodological issues and research activities at the core of this project have been deeply rooted in work carried out by the writer and his research team over the previous two decades at the University of Siena, along with further influences from wide-ranging international and academic partnerships (Campana \& Forte 2001; Campana \& Piro 2009; Musson et al. 2013). In the context of archaeological assessments in rural areas this project could perhaps be seen as an 'outrider' for what could be achieved in the Italian countryside by drawing upon approaches most extensively used up to now in the UK and in some parts of continental Europe (particularly Austria, Belgium, France and Germany). The aim is to encourage more sophisticated approaches to landscape archaeology in Italy and other parts of the Mediterranean world, replacing an essentially site-based approach by a more comprehensive 'landscape' perspective. The resultant picture would be less about 'sites' than about a populous landscape in the social, economic and environmental context, with field systems, communication routes, trade networks and industrial and agricultural foci in addition to domestic settlements - all seen as a developing process in the longue durée, the long-sought 'archaeological continuum' (Powlesland 2009; Gaffney et al. 2012; Keay et al. 2013).

A key aim within the Emptyscapes project is to strike a more sophisticated balance between 'site' and 'off-site' archaeology, bridging the two or expanding the concept of 'site' to include what might be called a 'catchment area', a block of landscape the size and position of which might change across time or in response to differing theoretical approaches or specific and archaeohistorical questions (see Powlesland 2009). However, within the present context the project's research strategy falls into four interlinked 'traditional' and 'innovative' categories that are summarised on the right-hand side of Figure 1, right.

Geographically, the project focuses on two sample areas in Central Italy: the lowland rural landscape around the hilltop Etruscan and Roman town of Rusellae, in South Tuscany near Grosseto (to be discussed here); and the now-rural but once-urban landscape of the ancient city of Veii in Central Latium, near Rome (Campana 2016). The Rusellae sample area can serve as a useful example the potential contribution of this approach to landscape studies within the needs and perspective of Planning Led Archaeology ${ }^{7}$.

Over the past decade a research team led by the author has been working on these and other sample areas, using a thoroughgoing 'landscape' approach based on systematic prospection aimed at

3. Matching of some features identified by the geophysical survey with a centuriation axes.

4. The reconstruction of centuriation pattern shows a close relationship between the intersections of axes and burial areas.

${ }^{7}$ For further information on the archaeological objectives leading the research in this area, the historical background and new answers and questions provided by this research: Campana, forthcoming. 
locating, identifying and documenting the archaeological resource in the chosen study areas. These two landscapes have been partially documented by multi-stage archaeological research involving an assessment of existing knowledge, field-walking survey and airborne remote sensing (satellite, airphotography and LiDAR prospection) plus - of particular relevance to the present discussion large- scale contiguous magnetic exploration so far covering 600 ha in all. Among other results, achieving 'archaeological continuum' is expected to push archaeological research activity from a predominantly reactive to a fundamentally proactive approach, introducing a new analytical level that could be defined 'mid-scale analysis' - representing a bridge between the more traditional 'microscale' of archaeological excavation and the 'large-scale' of regional survey, both of which inevitably fail to detect important evidence and relationships. Micro-, mid- and macro-scale studies are obviously complementarily, all three being necessary for a comprehensive interpretation. As has already been noted in this respect the University of Siena has from the 1970s onwards been carrying out a systematic programme of landscape and archaeological investigation within the Maremma area of southern Tuscany.

As a result, by the beginning of the present decade this area had a substantial database and GIS, developed mainly through the examination and analysis of 'traditional' analytical methods, including systematic field-walking survey and a significant number of open-area excavations (Francovich et al. 2000). After about 35 years of rigorous research work it seems reasonable to argue that this is among the most intensively studied areas within the Mediterranean world. However, despite the large amount of information assembled and examined over the years, it was obvious that the accumulated archaeological record shows some very clear gaps, both in space and time. It has been pointed out elsewhere (Campana 2009) that in this area, as in the rest of Tuscany and in other intensively studied parts of Italy such as Puglia and Lazio, $90 \%$ or even more of the collected evidence relates to the time span between the 6th century $\mathrm{BC}$ and the 6th century AD. Prehistory, the Iron Age and the Middle Ages thus remain poorly represented within the archaeological record produced by this kind of landscape survey.

Moreover, if we look at the 1:100,000 distribution map of the Rusellae area in Figure 2 and switch our attention from the 'sites' represented as yellow dots to the overall 'background' it is easy to appreciate how the 'empty spaces' predominate.

The situation becomes even worse if we view the same data at the more detailed scale of 1:10,000 in Figure 3. A map with this amount of 'emptiness' would be entirely inadequate as the basis for any kind of pre-development assessment in a similar area of open countryside. An attempt to fill some the yawning gaps in the map (so far as possible) has been made over the past four years through a programme of large-scale geophysical prospection within a sample transect between Grosseto and Rusellae, so far amassing about 370 ha of magnetic and 30 ha of resistivity data; intensive fieldwork during this same period has also been collecting archaeological, geoarchaeological and bio- archaeological evidence within this $25 \mathrm{~km}^{2}$ sample transect. 


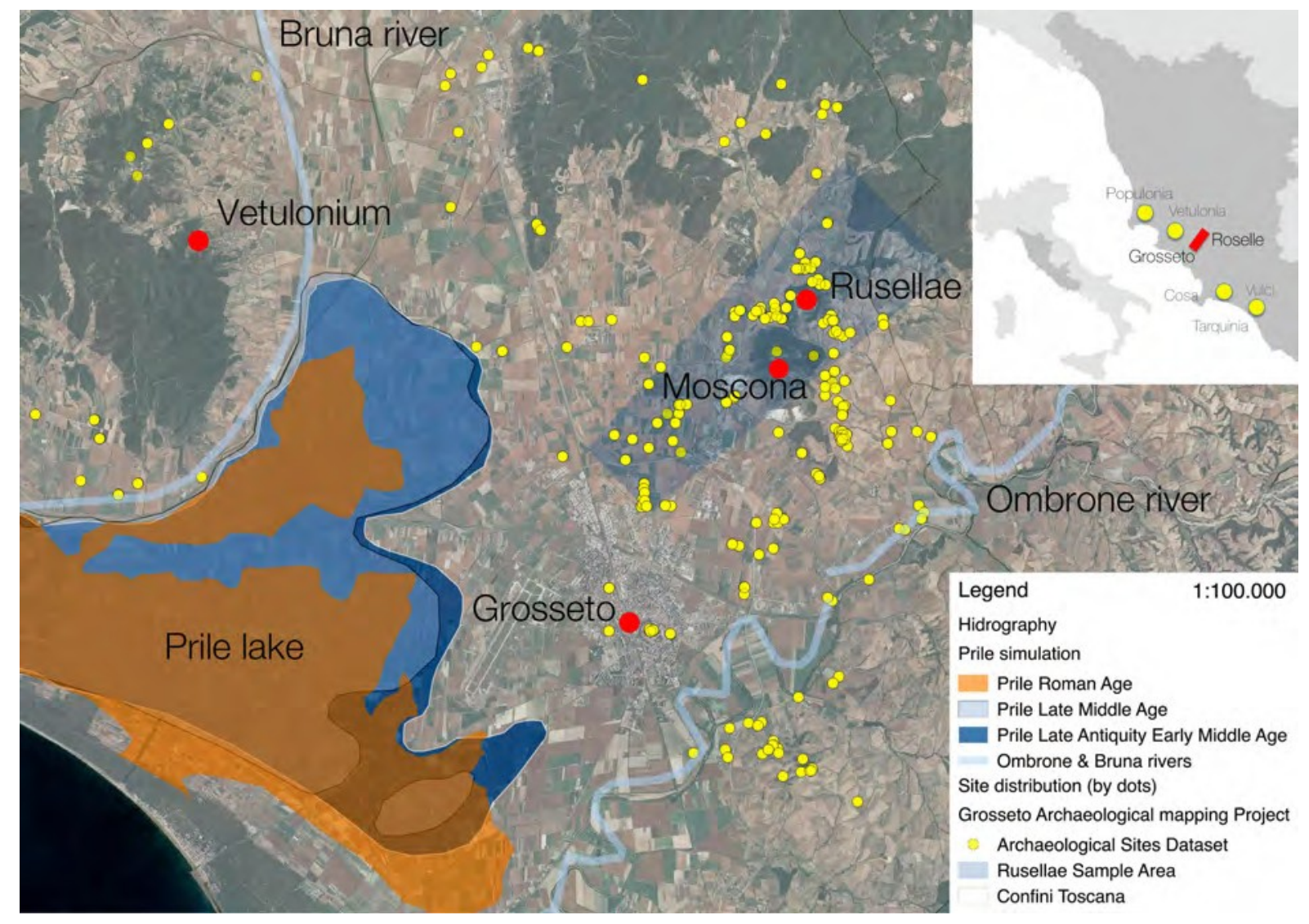

Figure 2. Archaeological distribution map of the Rusellae area, showing the results of three decades of archaeological survey work and mapping.

The gradually reducing extent of Lake Prile, which shrank in size from the first millennium $B C$ up to the end of the Middle Ages, is shown in solid colour.

So, after this amount of scientific effort have we in fact improved the overall picture? Have we made progress towards the goal of exploring the 'archaeological continuum'? Which new scenarios have been opened up from the point of view of landscape planning and predevelopment archaeological evaluation?

Bearing in mind that the project is still in progress, I think that is already possible to provide substantial answers to these questions presenting some examples that will shed light on the present impact on our understanding of the area and the overall potential of the holistic approach developed and implemented within this study of a carefully chosen tract of ancient landscapes. Starting from a quantitative remark, the systematic examination of past archaeological research, documentary sources, epigraphic material, place-name evidence and historical maps, combined with a long-lasting programme of field-walking survey, has produced a substantial amount of information on the Rusellae area - including around 80 archaeological contexts of various kinds within the transect now undergoing more intensive study (Figure 2).

However, moving from the 1:100,000 scale of Figure 2 to a more detailed representation at $1: 10,000$ in Figure 3, it is quite clear that even the most dense site concentration visible on 1:100,000 map displays large 'gaps' at the more detailed scale. The general increase in the 'visibility' of the archaeological evidence can be seen in the fact that systematic use of sources such as remote sensing (mainly based on aerial photography) and magnetometer and electrical resistance survey have so far produced 1886 previously undetected features within the sample transect. At present it is possible to recognize two main blocks of the sample transect within which we have so far been able to collect large-scale contiguous magnetic data, one in the southwest and the other to the north-east (Figure 3). It will be useful to start the analysis in the northeastern block. Aerial survey but especially magnetic prospection has thrown up entirely unexpected 
results. For instance, close below Rusellae itself, in an area of superficially undistinctive arable landscape, there is clearly visible in Figures 3 and 4 a mass of magnetic features representing a major road connecting the countryside with the city; this is around $6 \mathrm{~m}$ wide at the bottom of the slope but known to expand to a width of $14 \mathrm{~m}$ wide as it approaches the city itself.

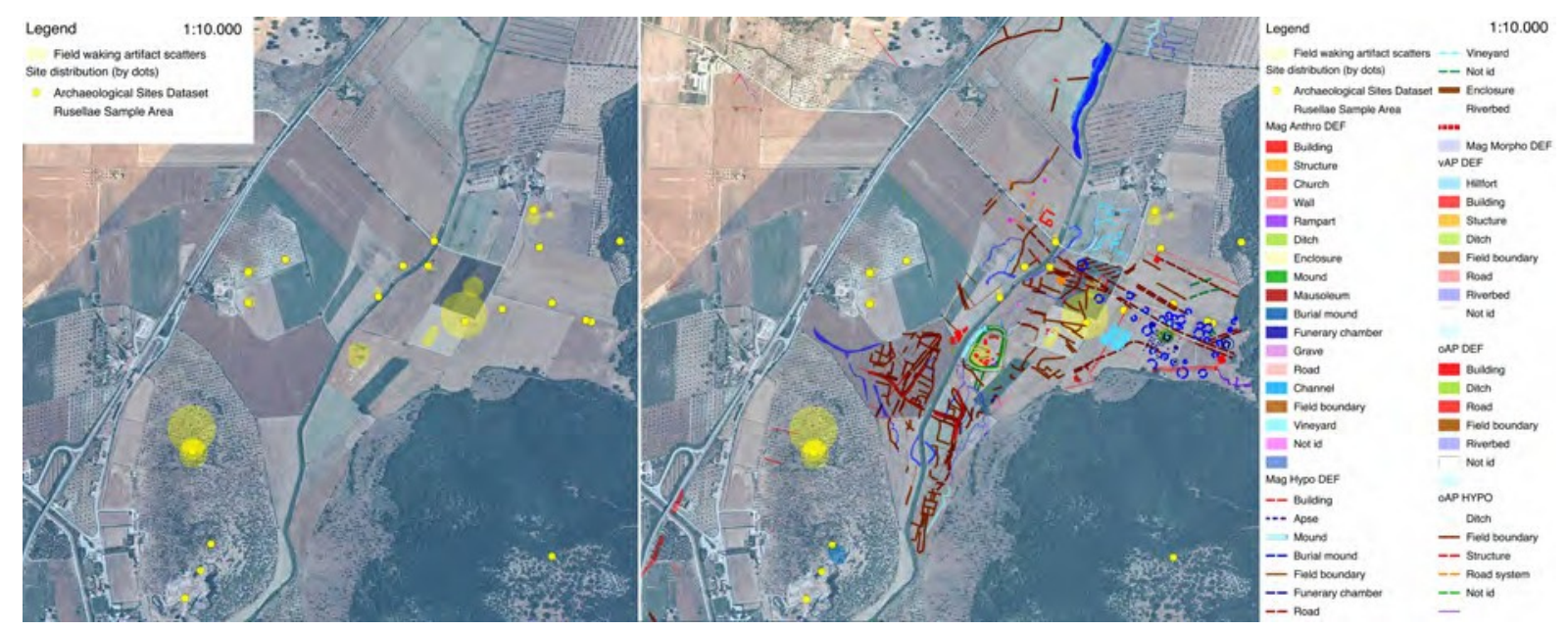

Figure 3. Left: distribution map of sites detected by 'traditional' archaeological survey towards the north- eastern end of the sample transect, at a scale of 1:10,000. Right: overlay of the site distribution and archaeological mapping of magnetic measurements (Mag) and oblique (OAP) and vertical (VAP) aerial photography.

Along both sides of this road the magnetic data shows a dense concentration of ring-ditches and rectangular anomalies that can without doubt be interpreted as burials, in effect the remains of a major cemetery probably dating to both the Etruscan and Roman periods. At present 34 ring-ditches and 37 rectangular anomalies have been recognized and mapped. The ring-ditches range from $13 \mathrm{~m}$ to $43 \mathrm{~m}$ in diameter and an average of $19 \mathrm{~m}$ while the square features are more standardised at about $4 \mathrm{~m}$ by $6 \mathrm{~m}$. On the basis of comparative studies on other Italian contexts such as Cerveteri (Tartara 2003: 157 166) this is clearly a major and previously unsuspected funerary landscape placed along one of the main roads entering and leaving the city of Rusellae. Moreover on the southern (lower left) edge of the Figure 4 it is possible to recognize another road and a quite peculiar structure showing as a round anomaly surrounded by a square of opposite magnetic polarity; the shape, articulation and size of this feature finds a convincing parallel in Roman mausolea (Johnson 2014). Significantly, but surprisingly in the light of this very striking geophysical evidence, neither micro-morphological evidence nor field-walking survey in the past or in the summer of 2015 (apart from a very limited scatter of mainly off-site material) presented any interpretable evidence of this kind of road system or long-lasting funerary landscape.

Moving a little further south (Figure 5) the magnetic measurements show a dense concentration of anomalies representing man-made functional elements and natural features within the local landscape: field systems, cultivation patterns, communication routes, buildings, geomorphological features and so on. Particularly interesting in this area is a double-ditched enclosure (green in Figure 5).

In this case field observation and artefact collection were very important in identifying a key feature of the site: a significant variation in elevation (of as much as $1.5 \mathrm{~m}$ ) matching the features visible on the magnetic map. Taking all of this evidence together the result is fairly obvious: an artificial mound or alternatively a ditched enclosure occupying a slight natural eminence in the local topography. Finds from field-walking indicated a flourishing occupation of the site within the $10^{\text {th }}$ to $12^{\text {th }}$ centuries $\mathrm{AD}$, while intense magnetic anomalies in the interior probably represent individual buildings, including one that might even have been a church. Close by, the magnetic data reveal an organised pattern of field boundaries, similar in general appearance to those associated with 
medieval settlements revealed by aerial photography on the Tavoliere di Puglia in the far southeast of Italy (Guaitoli 2003: 106-119).

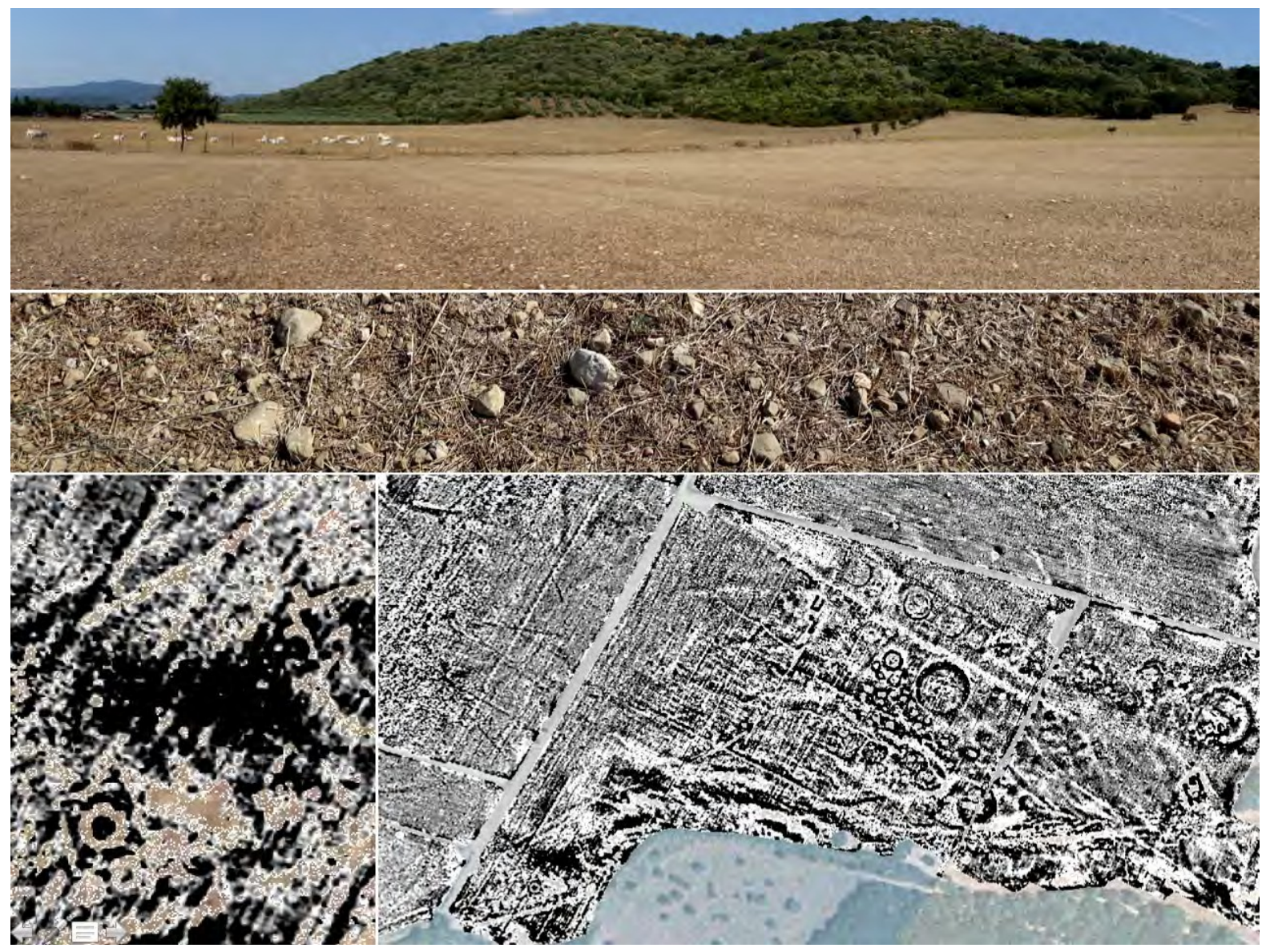

Figure 4. Geophysical data from the north-eastern part of the sample transect. From the upper left corner: general overview of the area; picture of the soil showing the extremely low concentration of artefact scatters; detail of the magnetic map showing the features interpreted as a possible mausoleum; general overview of the magnetic map displaying the large number of ring-ditches and square anomalies interpreted as a major cemetery lining either side of a road connecting the city of Rusellae to the surrounding countryside. The conjectured mausoleum appears at small scale in the bottom left corner of the lower-right map.

Moving further to the south-western block (Figure 5) within the sample transect the quantitative comparisons are equally remarkable. Previous survey work had identified 19 contexts (17 on-site and 2 off-site). Magnetic and electrical resistance prospection and aerial survey have now revealed a pattern of 883 features ranging chronologically from prehistory to the Middle Ages and varying from settlements to field systems, enclosures, graves, road systems, geomorphology and so forth. Figure 5 illustrates on the left side, the south-western part of the sample transect showing with yellow dots and polygons the results of 'traditional' archaeological investigation and on the right side integrated remote sensing data and GIS-based data mapping. The quantitative and qualitative improvement in the landscape database is clearly visible, making it possible to reduce substantially gaps and read the landscape in its continuity, providing an effective planning document.

Near the south-western end of the sample transect (Figure 5) air-photo evidence, geophysical survey and targeted field-walking survey have revealed a Roman villa complex and more recently a road system and a possible cemeteries, as well as a second ditched medieval enclosure, rectangular in this case and set at an alignment that hints at long-lasting persistence of the suspected Roman field system. It is useful to emphasise that two other ditched medieval enclosures have been identified in the Grosseto-Rusellae area in recent years, despite the previous absence of any comparable lowland sites after more than three decades of previous landscape survey based on the 
systematic application of the 'traditional' means available at the time (Campana et al 2006; Campana 2009). These totally unexpected lowland enclosures raise all sorts of questions about their origin and historical interpretation. It is entirely appropriate that the application of new survey strategies should pose academic questions. But the key point in relation to Planning Led Archaeology is that these previously 'invisible' settlements, roads, field systems, enclosures, graves, burial mounds and so forth would have been at risk of damage or destruction by development proposals if the Phase 1 archaeological evaluations had been conducted as an essentially 'desktop' exercise of the kind outlined at the beginning of this article.

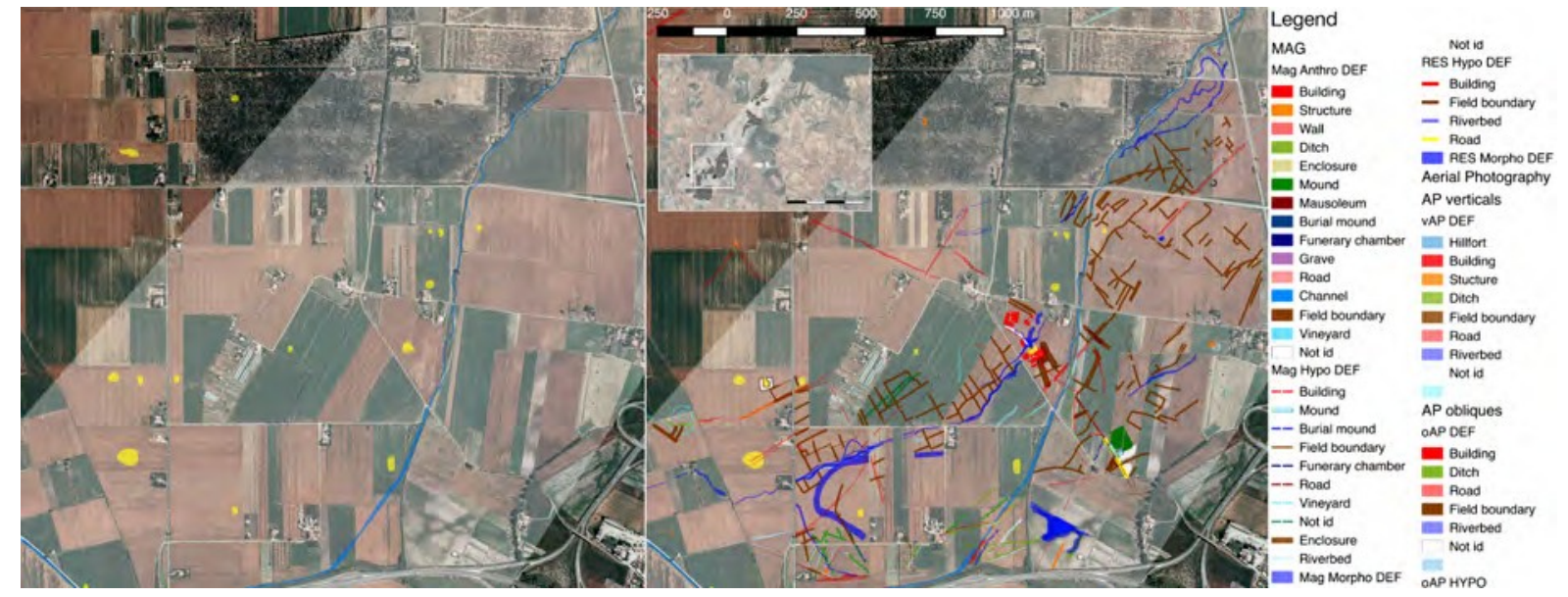

Figure 5. The south-western part of the sample transect. On the left side the results of 'traditional' archaeological investigation and on the right side mapping of the integrated remote sensing data.

\section{Conclusions}

To a degree it would be premature to claim that the results described above have established a new paradigm for landscape survey or for the practice of evaluation of rural areas within Planning Led Archaeology, at least until further work has created what might be called a 'critical mass' of similar or contrasting data. It is worth reiterating, however, that the application of these new methods in large- scale surveys elsewhere in Europe has radically transformed archaeologists' views about almost every aspect of the past within the areas concerned (Powlesland 2009; Gaffney et al 2013). The initial results from the BREBEMI and Emptyscape projects have nevertheless made a strong case for the potential effectiveness of this approach to rural landscape in at least some parts of Italy. The manner in which previously unsuspected features have been revealed across time has shown that the elusive 'archaeological continuum' is almost within our grasp even in the rather different environmental and archaeological conditions of the Mediterranean world. There are even internationally recommended guidelines for the application of these methods within a wide variety of different contexts (Schmidt et al. 2015) and there is an undeniable case for their increased use in Planning Led Archaeology.

One further observation might be appropriate here. Experience gathered so far, both within the academic environment and in development-related archaeology, has shown that within the Mediterranean area an absence of detectable human activity is very much the exception rather than the rule. The impact of this realisation should not be underestimated - it becomes a total misunderstanding to ask questions in terms of the presence or absence of evidence. In theory as well as in practice it is now widely accepted that almost every square metre of the landscape has been altered, directly or indirectly, by human intervention in the distant or more recent past (Broodbank 2013). As a consequence almost any development proposal is likely to have an impact on the surviving evidence of such activity.

Of course it would be foolish in this context to propose that development must not happen. This is clearly an untenable position, but how are we going to document archaeology at best and 
avoid or at least reduce the losses that must inevitably follow? Surely the finest protection would be the mandatory employment of strategies involving the use of the best available techniques for revealing these fragile traces of the past. Secondly, to make sense within Planning Led Archaeology, this approach ought to be implemented as an obligatory part of Phase 1, in advance of any planning decision being made. This phase of the process needs to be substantially reinforced so as to provide a secure basis for making well-informed choices before development work begins on site. For archaeologists, planners and developers alike this would offer the opportunity of reducing damage, destruction and delay as well as helping in the formulation of consistent policies for cultural and landscape sustainability in the longer term.

\section{Acknowledgements}

The author owes a huge debt of gratitude to the BREBEMI company for the great opportunity and trust provided by the president Dr Francesco Bettoni, the general director Prof Bruno Bottiglieri, the chief of the rescue archaeology bureau Dr Paola Rigobello and the company's chief engineer Dr Lorenzo Foddai. The author is further indebted to the SoIng company, in particular to Annalisa Morelli, Gianfranco Morelli and Giovanni Bitella, as well as to Iacopo Nicolosi at the Italian National Institute of Geophysics and Vulcanology. Grateful thanks also go to Klaus Leidorf of Luftbilddocumentazion in Germany. All of these friends and colleagues contributed to the successful conduct and management of the field investigations and to the overall outcome of the project.

The Emptyscapes project would not have been possible without the financial support of the Marie Curie action (FP7-PEOPLE-2013-IEF n. 628338) and the Culture 2007 ArchaeoLandscpes Europe project (Grant Agreement nr. 2010/1486/001-001).

Regarding the Emptyscapes project particular thanks are offered to Prof Martin Millett (University of Cambridge), Ken Saito (University of Siena), Dr Emanuele Vaccaro, Prof Marcello Guaitoli (CNR and the University of Salento), Dr Salvatore Piro (CNR-ITABC), Michel Dabas (Geocarta) and Gianfranco Morelli (Geostudi) for their valuable support in various aspects of the research.

Sincere thanks are also due to the Archaeological Soprintendenza of Lombardy and Tuscany, and in particular to Raffaella Poggiani-Keller, Andrea Pessina and Gabriella Poggesi for their openmind intellectual debate and problem solving approach.

I am particularly grateful, too, to the team of the Laboratory of Landscape Archaeology and Remote Sensing at the University of Siena and the spin-off company ATS srl: Cristina Felici, Matteo Sordini, Francesco Pericci, Lorenzo Marasco, Barbara Frezza, Mariaelena Ghisleni, Anna Caprasecca and Francesco Brogi.

Special thanks are also due to the president of the Superior Consiluim of Cultural Heritage Prof Andrea Carandini, to director Prof Giuseppe Sassetelli and the members of the Scientific Committee for Italian Archaeology, and lastly to the General Director of the Soprintendenza, Dr Stefano De Caro, for providing the opportunity to discuss our project within the Ministry of Cultural Heritage.

Finally, heartfelt thanks go to two special friends who have followed and inspired so much of the writer's research work since early in his career, Chris Musson and Prof Dominic Powlesland. As ever, they have helped with constructive criticism and comments throughout all stages of the work described here. 


\section{References}

BINTLIFF, J. \& A. SNODGRASS. 1988. Mediterranean survey and the city. Antiquity 62: 57-71. BROODBANK, C. 2013. The Making of the Middle Sea a History of the Mediterranean from the Beginning to the Emergence of the Classical World. New York: Thames \& Hudson.

CAMPANA, S. 2009. Archaeological Site Detection and Mapping: some thoughts on differing scales of detail and archaeological 'non-visibility', in S. Campana \& S. Piro (ed.) Seeing the unseen: 5-26. The Netherlands: Taylor \& Francis.

CAMPANA, S. 2016. Filling gaps in space and time at Veii. 'Emptyscapes' project interim report. In Cerasuolo, O. \& J. Tabolli. Veii - An Etruscan City. University of Texas Press.

CAMPANA, S. Forthcoming. EMPTYSCAPES. Filling 'empty' Mediterranean Landscapes, Mapping the Archaeological continuum: Rusellae case study.

CAMPANA S. \& M. Forte (eds.) 2001. Remote Sensing in Archaeology. Florence: All'Insegna del Giglio.

CAMPANA, S., R. FRANCOVICH \& L. MARASCO. 2006. Remote Sensing and Ground-truthing of a Medieval Mound (Tuscany - Italy), in S. Campana \& M. Forte M. (ed.) From Space to Place: 491-496. Oxford: Archaeopress.

CAMPANA, S. \& S. PIRO (eds.) 2009. Seeing the unseen. The Netherlands: Taylor \& Francis.

CAMPANA S. \& M. DABAS. 2011. Archaeological Impact Assessment: The BREBEMI Project (Italy). Archaeological Prospection 18: 139-148.

CARVER, M., B. GAYDARSKA \& S. MONTON-SUBIAS (eds.) 2015. Field Archaeology from Around the World. Ideas and Approaches. New York: Springer.

FRANCOVICH, R., A. PELLICANÒ \& M. PASQUINUCCI (eds.) 2000. La carta archeologica. Fra ricerca e pianificazione territorial. Florence: All'Insegna del Giglio: 83-116.

JOHNSON, M.J. 2014. The Roman Imperial Mausoleum in Late Antiquity. Cambridge: Cambridge University Press.

KEAY, S., G. EARL, G. BEALE, N. DAVIS, J. OGDEN, K. STRUTT, F. FELICI, M. MILLETT, S.

KAY \& R. CASCINO. 2013. Challenges of port landscapes. Integrating geophysics, open area excavation and computer graphics visualization at Portus and the Isola Sacra, in P. Johnson \& M. Millett (ed.) Archaeological Survey and the City: 303-357. Oxford: Oxbow books.

GAFFNEY, C., V. GAFFNEY, W. NEUBAUER, E. BALDWIN, H. CHAPMAN \& P. GARWOOD. 2012. The Stonehenge Hidden Landscapes Project. Archaeological Prospection 19 (2): 147-155.

GREENE, K. \& T. MOORE. 2010. Archaeology: An Introduction. Routledge.

GUAITOLI, M. 1997. Attività dell'Unità operativa Topografia antica. Metodologie di catalogazione dei beni archeologici, Beni archeologici-Conoscenza e tecnologie. Quaderno 1 (2): 9-50.

GUAITOLI, M. (ed.) 2003. Lo sguardo di Icaro. Roma.

GULL, P. 2015. Archeologia Preventiva. Il codice degli appalti e la gestione del rischio archeologico. Palermo: Dario Flaccovio Publisher.

MUSSON, C., R. PALMER \& S. CAMPANA. 2013. Flights into the Past. Aerial photography, photo interpretation and mapping for archaeology. Available at:

http://archiv.ub.uni- heidelberg.de/propylaeumdok/2009/1/flights_into_the_Past_2013.pdf (accessed 29 February 2016).

POWLESLAND, D. 2009. Why bother? Large scale geomagnetic survey and the quest for "Real Archaeology" in S. Campana \& S. Piro (ed.) Seeing the unseen: 167-182. The Netherlands: Taylor \& Francis.

SCHMIDT, A., P. LINFORD, N. LINFORD, A. DAVID, C. GAFFNEY, A. SARRIS \& J.

FASSBINDER (eds.) 2015. EAC Guidelines for the Use of Geophysics in Archaeology. Questions to Ask and Points to Consider. Available at: http://european-archaeological- council.org/files/eac_guidelines_2_final.pdf (accessed 29 February 2016).

TARTARA, P. 2003. Ortofotopiano storico IGM 1930 del territorio tra Cerveterei e la costa, in Guaitoli M. (ed.) Lo sguardo di Icaro: 157-166. , Roma. 